\title{
Discussing Relations Between Dynamic Business Environments and Big Data Analytics
}

\author{
Daniel Staegemann*, Matthias Volk, Christian Daase, \\ and Klaus Turowski \\ Faculty of Computer Science, Otto-von-Guericke-University, Magdeburg, Germany \\ daniel.staegemann@ovgu.de, matthias.volk@ovgu.de, \\ christian.daase@st.ovgu.de, klaus.turowski@ovgu.de
}

\begin{abstract}
Big data attracts researchers and practitioners around the globe in their desire to effectively manage the data deluge resulting from the ongoing evolution of the information systems domain. Consequently, many decision makers attempt to harness the potentials arising with the use of those modern technologies in a multitude of application scenarios. As a result, big data has gained an important role for many businesses. However, as of today, the developed solutions are oftentimes perceived as completed products, without considering that the application in highly dynamic environments might benefit from a deviation of this approach. Relevant data sources as well as the questions that are supposed to be answered by their analysis may change rapidly and so do subsequently the requirements regarding the functionalities of the system. To our knowledge, while big data itself is a prominent topic, fields of application that are likely to evolve in a short period of time and the resulting consequences were not specifically investigated until now. Therefore, this research aims to overcome this paucity by clarifying the relation between dynamic business environments and big data analytics (BDA), sensitizing researchers and practitioners for future big data engineering activities. Apart from a thorough literature review, expert interviews are conducted that evaluate the made inferences regarding dynamic and stable influencing factors, the influence of dynamic environments on BDA applications as well as possible countermeasures. The ascertained insights are condensed into a proposal for decision making, facilitating the alignment of BDA and business needs in dynamic business environments.
\end{abstract}

Keywords: Business IT Alignment, Dynamic Business Environments, Data Analytics, Big Data, Systems Engineering.

\footnotetext{
* Corresponding author

(C) 2020 Daniel Staegemann et al. This is an open access article licensed under the Creative Commons Attribution License (http://creativecommons.org/licenses/by/4.0).
}

Reference: D. Staegemann, M. Volk, Ch. Daase, and K. Turowski, "Discussing Relations Between Dynamic Business Environments and Big Data Analytics," Complex Systems Informatics and Modeling Quarterly, CSIMQ, no. 23, pp. 58-82, 2020. Available: https://doi.org/10.7250/csimq.2020-23.05

Additional information. Author ORCID iD: M. Volk - https://orcid.org/0000-0002-4835-919X. PII S225599222000136X. Received: 24 July 2020. Accepted: 30 July 2020. Available online: 31 July 2020. 


\section{Introduction}

While data have, at least to some extent, always played a role in the business world, the ability to gather and utilize them has dramatically increased over the course of the last two decades [1]. As an answer on modern technological demands, the term big data has emerged, starting its journey in early 2000's with the introduction of the "Google File System" [2]. Since then a confluence of promising technologies, techniques, paradigms and algorithms occurred, influencing a vast array of domains in multiple ways. A non-exhaustive list of application areas that especially influences the way companies operate, comprises such areas as industry 4.0 and IoT [3], transportation [4], supply chain management [5], the evaluation of mergers and acquisitions [6] as well as the analysis of information provided by news outlets and social media [7].

While there are significant differences in the encompassed tasks, in each case the incorporation of relevant information into the respective processes was expected to yield noticeable benefits. Apart from the overall increase of revenue by providing new or enhanced services, this includes many more avenues, as, for instance, improvements of organizational activities, such as monitoring, optimizations or decision making [3], resulting in noticeable competitive advantages. This esperance is supported by many researchers [8]-[12], including Müller et al. [13], who conducted a corresponding study to quantify this effect. In the course of their work, they found that the use of big data is associated with an average productivity increase of approximately four percent. Subsequently, there is a huge number of publications dealing with the topic of big data [14].

\subsection{Big Data Analytics}

As highlighted, big data analytics (BDA) is used for multiple reasons in numerous application areas, aiming to process large amounts of differently structured data, sometimes even in realtime [15]. A few years ago, only the volume of the data was relevant, and conventional data warehouses appeared to be sufficient for the storing and analysis of the internal company data [16]. Yet, in the following years, different other data characteristics emerged, forcing researchers as well as practitioners to alter and create new paradigms, analysis methods and technologies, capable to overcome limitations of currently existing approaches. Apart from the previously referred amount of data (volume), this includes, for instance, the variety, velocity and veracity of the data [15]. Likewise, to the definition of the term big data itself, most of the characteristics encompass different meanings. The variety of the data mostly refers to the heterogeneity of the structure [17], [18], but sometimes also its origin [15]. The same applies to the velocity that pertains to the speed with which the data is incoming as well as the time for its processing [15], [18]. Furthermore, the veracity focuses on the reliability and trustworthiness of the data. A general overview, comprising some of the most relevant expressions is depicted in Figure 1. However, those core characteristics, also labelled the four Vs of big data, represent only an excerpt of the general amount of existing data characteristics [19]. Others focus, for instance, on the value of the data or the variability of the other characteristics, such as the structure, data source and flow rate [15], [17]. Generally, big data can be characterized as "data sets and analytical techniques in applications that are so large [...] and complex [...] that they require advanced and unique data storage, management, analysis, and visualization technologies" [20].

As one can note, the consideration of only a single characteristic and its severity cannot be seen in an isolated way or treated equally across different systems, since it is always an interaction of multiple facets. Consequently, sometimes additional methods for data cleansing, preparation and transformation might be required, for instance, if new data from previously unknown or unreviewed sources is considered. The diversity of the characteristics, both from the separate consideration as well as their combination, leads not only to a certain uniqueness of a big data application but also to an increased complexity. This circumstance can easily be illustrated by the comparison of two different cases that take only two different characteristics 
into account. The system architectures of a potential big data solution for the batch processing of petabytes of data can be entirely different compared to a solution that is intended to stream process gigabytes of data, maybe also originating from different sources. Therefore, it does not seem to be surprising that in most of the cases, neither the planning and implementation of related projects nor the system's operation is a trivial undertaking. This is exacerbated by the socio-technical nature of big data applications, combining the capabilities of the involved people, the injected data and the technical implementation [21]. The latter, whose realization can be summarized under the term big data engineering [22], represents one of the most important dimensions. It includes, inter alia, the planning and structuring of the system under development, as well as the capabilities that are to be provided. Those could, for instance, comprise such capabilities as sentiment analysis [23], prediction engines [24], machine learning [25], text analytics [26], complex calculations [27] or numerous other operations whose findings are deemed beneficial to facilitate a business's success.

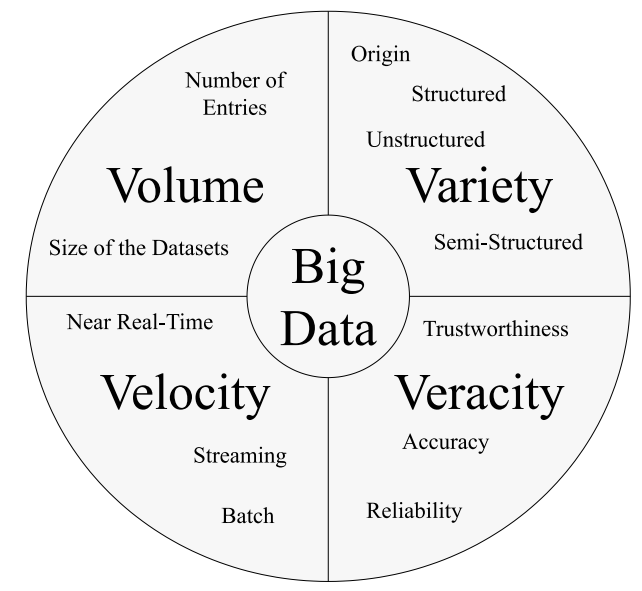

Figure 1. The four main data characteristics of big data

As in the general nature of information systems, the system itself does not create any value [28] but rather the use of it. The same applies for big data systems. The actual value creation is realized through the incorporation of knowledge that can be achieved by the analysis of the data through the developed solutions. However, a deficiency regarding the technical implementation may have unforeseen consequences and therefore a huge impact for the general applicability of the solution. Besides faulty implementations, those deficiencies might also occur through the deprecation of the application, which is especially likely when it is subject to a highly dynamic business environment [29].

\subsection{Dynamic Business Environments}

Not only systems and their implementations experience an ongoing evolution, the same applies for numerous businesses [30] and the environments they are operating in. This can be linked to a variety of factors from natural causes and new scientific or technological advancements to changes regarding the market conditions, customers' preferences, fluctuating competition and new legal frameworks. As a result, there are numerous strategies for dealing with this situation. Accordingly, there is also a vast body of scientific literature dealing with this phenomenon [29], [31]-[35]. While this situation constitutes a significant challenge to organizations, it also allows for the differentiation from the competition through superior adaptability, as well as for the development of new business segments. Concluding those considerations, it can be stated that in the context of business, "dynamic environments are characterized by constant rate of change and flux that open up opportunities and market niches" [36]. 
In a global economy that grows more and more connected and therefore opens up businesses to an increasing number of influences, those dynamic environments require a certain adaptability not only from relevant stakeholders but also from the systems that are used for operational activities. This, however, puts emphasis on the importance of the continuous readjustment of the alignment between business and IT, which "refers to applying Information Technology (IT) in an appropriate and timely way, in harmony with business strategies, goals and needs" [37]. Furthermore, this not only applies to traditional and often rather generic IT infrastructure, but also to highly sophisticated and specialized systems such as BDA solutions.

\subsection{Research Goal}

Despite the aforementioned vast body of literature, to our knowledge, the implications of highly dynamic business environments on the implementation and operation in the domain of BDA have not yet been covered sufficiently. To overcome this paucity and facilitate the abovementioned alignment, this article will discuss their relationship and highlight potential consequences and responses. Hence, the main goal of this research is not only to provide an overall overview about influences of dynamic business environments, particularly focusing on big data analytics applications, but also on general mistakes during the corresponding implementation and possible countermeasures that could be performed. Thus, the main research question $(\mathrm{RQ})$ is the following.

RQ: What are the effects of dynamic business environments on big data analytics solutions and how can businesses take them into account?

To find a suitable answer to this RQ, it is at first required to understand which factors signify a dynamic business environment and how those environments differ from stable ones, resulting in the first sub research question (SRQ).

SRQ1: What are stable and dynamic business environments with regard to big data analytics?

Afterwards, the influence of those dynamic business environments on big data solutions needs to be thoroughly investigated, constituting the focus of the second SRQ.

SRQ2: How does a dynamic business environment affect big data analytics solutions?

Finally, the third and last SRQ focuses potential strategies to deal with those identified effects.

SRQ3: Which strategies and countermeasures could be applied to mitigate the difficulties when it comes to the implementation of big data analytics solution in dynamic business environments?

\subsection{Structure}

To find answers to the research questions, the contribution at hand is structured as follows. Ensuing the Introduction, which also comprises explanations for the key concepts big data and dynamic business environments, Section 2 provides details about the methodologies used in the context of this work. In particular a structured literature review as well as expert interviews were carried out, not only to obtain an overview about the current state of the art but also to stepwise validate and discuss the results originating from this work and to gain additional insights. Following this foundational information, in Section 3, a thorough analysis of dynamic business environments in the big data context is conducted. Throughout this section, the respective results of the interviews as well as the literature review are applied. At first, the dynamic of businesses 
in the big data context is delimited, providing an answer to SRQ1. This is followed by the examination of the consequences of rapidly evolving business environments, which corresponds to $S R Q 2$. In Section $4 S R Q 3$ is answered, in particular, possible strategies and countermeasures to mitigate the challenges accompanying BDA in dynamic business environments are presented. The work eventually closes with a short recapitulation and some concluding remarks in Section 5.

\section{Methodology}

The methodology of this research is based on three major factors. The first one is the use of reasoning to deduce and justify certain aspects. Furthermore, a structured literature review provides a comprehensive overview of the state of the art. As a third source of insights, experts interviews have been conducted, providing additional knowledge and also helping to evaluate the findings.

\subsection{Structured Literature Review}

To evaluate how companies already handle the dynamic nature of certain big data sources and processing systems, and what consequences may result from this, a structured literature review (SLR), which "distills the existing literature [...] to summarize the state of the art in this subject field" [38], is conducted. The SLR proves to be particularly useful in this research, because it combines the two areas of big data and dynamic business environments, which have already been considered separately by researchers, but less in connection, as the results in Section 3 show. In doing so, a theoretical background is provided and the breadth of the already existing research can be shown and practical questions answered [39]. According to [38], the review follows five consecutive steps, beginning with the scanning of all available publications for strictly specified key phrases in a well-defined time period. During this first step, relevant information is extracted in the form of notes, including secondary topics revolving around the main topic [38]. Although it is done simultaneously to the scanning process, according to the authors of these guidelines, taking notes is to be considered as a second step. Subsequently, originating from these notes, a concept map is drawn as a third step. Because the objective of this review is only a summary of the state of the art and not a stand-alone systematic literature review, the concept map only consists of three nodes, as depicted in Figure 2. Starting from the main topic, referred to as big data in dynamic business environments with the concept map ID (CM-ID) number 1, two secondary topics could be identified, which were frequently included in the primary literature by the authors. These derived subject areas are big data analysis challenges and big data mining with dynamic sources. Because of their presumably lower relevance to the main topic, only the first twenty available research articles found, using the corresponding database queries (automatically ordered by relevancy), are considered in the SLR. The writing of the literature review itself takes place as the fourth step and finally, as the fifth step, the bibliography is added at the end of this document.

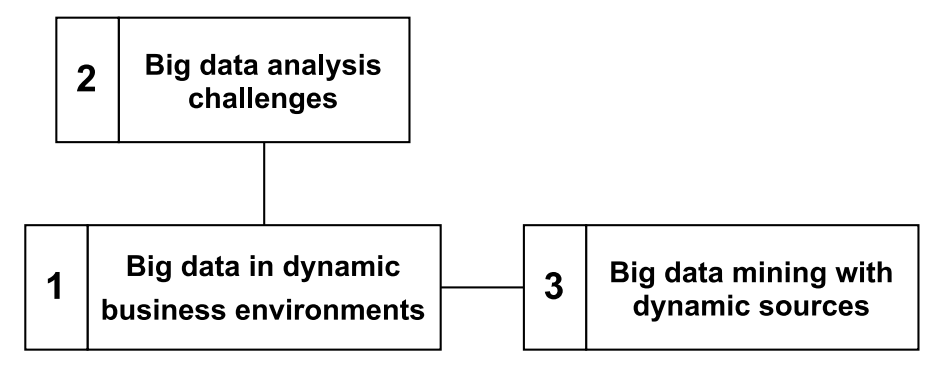

Figure 2. Concept map of the conducted SLR 
The strict specification of the conducted search is necessary in order to meet the scientific standards that a literature review must fulfil [40]. In particular this includes that it is systematic, explicit and comprehensive, so that other researchers are able to decide whether the review sufficiently covers their own field of interest [39]. As depicted in Table 1, the scientific databases Scopus and Springer Link were selected for the search. Although Scopus only provides abstracts and bibliographic data, the results combine references to literature found in a variety of full text databases such as IEEE Xplore, ACM Digital Library and ScienceDirect. However, since previous test searches have shown a lack of references to publications provided by Springer, this specific database is additionally used for the search. In Scopus, the search parameters focus on the title, keywords and abstracts of the available publications, ranging from 2014 to 2020. Depending on the entry of the concept map they differ partly in terms of the used keywords. However all of them had the keyword big data in common. For CM-ID 1, the focus was put on the keywords dynamic business or dynamic environment. The second entry covered analytics challenges whereas the third entry used a combination out of data mining and dynamic. Springer, in turn, required some changes in the query due to its slightly different advanced search. The term big data had to be entered in the title search field, and two separate searches had to be performed for the first concept map entry, one with the term dynamic business and one with dynamic environment in the search field for an exact phrase somewhere in the document. For the other two concept map entries, the search was carried out analogously. Besides the shown input parameters, further criteria for evaluating the significance of the found publications are established, which are listed in Table 1. In particular those comprise the inclusion and exclusion criteria of the search and refinement process. It was strictly required that all inclusion criteria were fulfilled, contrary to that, whenever one of the exclusion criteria was applicable the paper was not further considered.

Table 1. Inclusion and exclusion criteria

\begin{tabular}{|l|l|}
\hline \multicolumn{1}{|c|}{ Inclusion Criteria } & \multicolumn{1}{c|}{ Exclusion Criteria } \\
\hline Only completed research & Early-access papers \\
\hline Conference or journal paper, or (for CM-ID 1 only) review & Outside the first 20 entries (for CM-ID 2 and 3) \\
\hline Written in English & Specific study without theoretical contributions \\
\hline Satisfying theoretical background & Duplicates \\
\hline Field of application similar to business environment & Dynamic in terms of hardware specifications \\
\hline
\end{tabular}

The criteria demanding only completed research papers from conferences, journals or reviews, as well as the special criterion for CM-ID 2 and 3, were applied before the total hits were counted. Figure 3 therefore already shows the filtered number of hits according to these criteria.

The characteristics, challenges and consequences of big data analytics in dynamic business environments, derived from the ten articles meeting these criteria, are discussed in Section 3. There, the results are divided into two categories: predictable and unforeseeable consequences. Findings from publications complying with the search parameters of the secondary nodes, indicated in Figure 3 with the CM-IDs 2 and 3, are also taken into account with explanations, how the requirements for successful data acquisition and analysis would change in a dynamic environment.

\subsection{Expert Interviews}

Before the actual questioning started, initial warm-up questions were asked, focusing not only on the current position but also the overall work experience and the self-perceived experience in the related subdomains. In terms of the latter, a range from 1 to 10 was provided, at which 1 induced a very low level of knowledge and 10 a very high level. However, it has to be taken into account, that those self-evaluations are highly subjective and not necessarily completely reflective of the actual degree of competence. Additionally, one has to note that the given time of work 
experience includes only the time after the studies, even though some of the interviewees already collected initial experience before or concurrently to being university students. An overview about the background information of each interviewee is summarized in Table 2. On average, each expert interview had a duration of about 40 minutes.

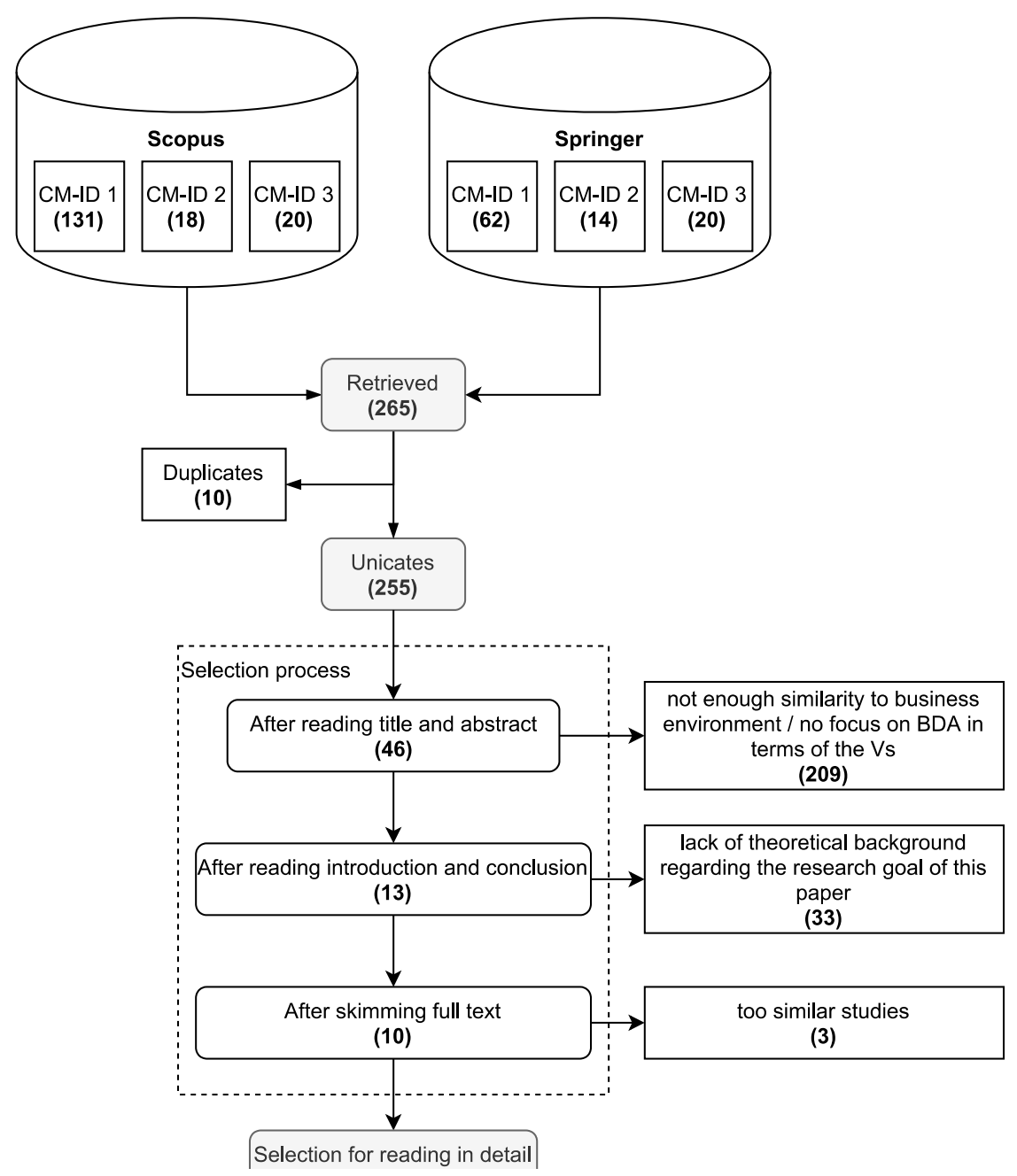

Figure 3. Literature review search workflow

All questions asked during the interview were focused on the aforementioned SRQs and are shown in Table 3. The initial four questions were concentrating on the made inferences of SRQ1. Besides the assessment of the overall sensibility, the interviewees were asked to perform tangible ratings on each of the factors depicted in Table 4. In here a range from 1 to 10 was utilized, following the recommendation by [41]. All other questions related to the SRQs in a similar way. The questions five and six were focusing on SRQ2 and the remaining - on SRQ3. Except of the closed-ended question nine and the numerical rating in question four, all others were formulated as open-ended questions. Furthermore, sometimes the interviewees somewhat digressed from the given questions; that, however, turned out to be a valuable source of additional insights. 
Table 2. Information about the interviewed experts. The given self-perceived experience ranges from low (1) to high (10).

\begin{tabular}{|c|c|c|c|c|c|}
\hline \multirow{2}{*}{ No. } & \multirow{2}{*}{ Position } & \multirow{2}{*}{ Work Experience } & \multicolumn{3}{|c|}{$\begin{array}{l}\text { Self-perceived } \\
\text { Experience }\end{array}$} \\
\hline & & & Business & IT & $\begin{array}{c}\text { Big } \\
\text { Data }\end{array}$ \\
\hline 1 & Big data architect in a large European insurance company & 6 years & 9 & 7 & 7 \\
\hline 2 & $\begin{array}{l}\text { Previous managing director of an IT system company } \\
\text { (ERP/BI/etc.) }\end{array}$ & 40 years & 9 & 8 & 5 \\
\hline 3 & Project manager at a large IT service company & 8 years & 7 & 10 & 6 \\
\hline 4 & $\begin{array}{l}\text { Lead product manager at a large accounting service } \\
\text { provider }\end{array}$ & 10 years & 4 & 8 & 4 \\
\hline
\end{tabular}

Table 3. All asked questions and their respective answer type

\begin{tabular}{|l|l|l|}
\hline No. & Question & Type \\
\hline 1 & $\begin{array}{l}\text { How do you gauge the concept, to rate a business environment whether it is rather static } \\
\text { or dynamic? }\end{array}$ & Open-Ended \\
\hline 2 & $\begin{array}{l}\text { Do you think that the following factors (cf. each entry in Table 4) are sensible to } \\
\text { distinguish between static and dynamic business environments? }\end{array}$ & Open-Ended \\
\hline 3 & $\begin{array}{l}\text { Do you miss any factors that were not mentioned in the aforementioned question (cf. } \\
\text { Table 4)? If so, please name and describe why you consider them to be important. }\end{array}$ & Open-Ended \\
\hline 4 & $\begin{array}{l}\text { How would you rate the importance of each factor (cf. Table 4) on the behavior of the } \\
\text { business environment whether it is rather static or dynamic? In doing so, for each factor a a } \\
\text { value ranging from 1 to 10 can be given, where 1 indicates a very low influence and, vice } \\
\text { versa, 10 a very high influence. }\end{array}$ & Numerical \\
Rating
\end{tabular}

While most of the results are interwoven within the following course of this work, explicit results are primarily addressed in Sections 3 and 4. The main reason for this emerges out of the main focus of the interviews itself, where findings from the contribution at hand are discussed. 


\section{Dynamic Business Environments in the Big Data Context}

In order to clarify the relation of dynamic business environments and BDA and to find suitable answers to the previously defined RQ and SRQs, within this section, the relation between dynamic business environments and big data is thoroughly investigated. In doing so, the results of the earlier introduced methodologies are presented and interwoven in the overall research discourse. At first, the aspects that determine the dynamicity of a business environment in the context of BDA are explored. Subsequently, predictable and unpredictable consequences of dynamic businesses environments are discussed, followed by a consideration of their implications for BDA.

\subsection{Delimiting the Dynamic of Businesses}

Even though most companies can benefit from an advanced use of information resources, the particular business premises and needs can vastly differ, also resulting in diverse avenues for enrichment through big data. For instance, the monitoring of the production machines in a factory is relatively stable. There is a set of well-understood and familiar machinery, which produces sensor data whose structure is constant over time and usually only changes when a new type of device is introduced. While this can certainly fall into the category of big data if the assemblage gets complex enough or there are high requirements regarding the velocity [42], a once implemented application can be used for a long time without noticeable degradation or aging.

In contrast, a dynamic situation exists when the underlying factors permanently evolve. As a result, a system is either never truly finished or it gets more and more outdated with every change to the business reality. This situation was also emphasized in the course of the expert interviews. A typical area where this occurs is the analysis of social media posts and news. For instance, the author of [43] described how the analysis of news articles can help companies in identifying potential threats to their supply chain and act accordingly before possible competitors are even aware, therefore giving them the edge by increasing their reaction speed. However, the relevant set of data sources is in a constant state of flux and the same applies to social media. New competitors arise, some might go out of business and others could change their content, quality or just the technical implementation, resulting in a need to overhaul the way the corresponding data are garnered by the analytics system. Furthermore, other markets might become of interest, requiring the addition of new sources or even the incorporation of new languages. Additionally, also the usage of already implemented languages might change over time, resulting in the emergence of new abbreviations, slang or proper names. Moreover, language can be context-sensitive, posing another challenge, especially, when the context cannot be explicitly conveyed but has to be initially aware to the recipient [44]. An example would be the limited amount of characters when using twitter, or even more severe, the use of hashtags [45]. While in 2018 the hashtag \#corona would have almost certainly referred to a brand of beer, in the second quarter of 2020 it is highly likely that the corresponding pandemic is meant. Even in cases where the input data are not noticeably changing, especially when they are unstructured, the analysis does often not provide a perfect accuracy [44]. Subsequently, a later modification or replacement might be necessary or at least desirable.

Besides those factors regarding the data and their processing, also the relevant business questions itself can change, requiring either a modification of the BDA system or remaining unanswered. While some businesses might only need the same information and analyses over a long period of time, resulting in a system that needs no major changes regarding that aspect, others can be reliant on frequently changing insights. As a result, the latter ones also need to constantly extend or adapt their analytics capabilities. Furthermore, also the long-term predictability of the organization's and its line of work's development as well as the surrounding circumstances can have an influence on a BDA solution. While in some cases, new requirements, 
constraints or opportunities can be planned for well in advance, others are rather unpredictable. This applies, for instance, to the social media domain, where not only the meaning of the data can change frequently, but also certain events can highly influence the data generation itself [46], [47]. Additionally, during the interviews, the organizational structure emerged as another important factor, with highly hierarchical and complex ones usually resulting in slower reaction speeds and more complicated processes compared to businesses with flat structures. A summary of those six identified major factors, respectively dimensions, contributing to an either stable or dynamic business environment is shown in Table 4.

Table 4. Factors influencing the character of a big data analytics solution

\begin{tabular}{|l|l|}
\hline \multicolumn{1}{|c|}{ Stable } & \multicolumn{1}{c|}{ Dynamic } \\
\hline Business questions remain the same & Frequently new business questions \\
\hline No major changes regarding the data sources & Frequent changes regarding the data sources \\
\hline Meaning of obtained data does not change & Data are context-dependent \\
\hline Algorithms have high maturity & Algorithms are rapidly improving \\
\hline Developments are highly predictable & Little long-term planning security \\
\hline Highly hierarchical organizational structures & Flat organizational structures \\
\hline
\end{tabular}

Oftentimes, when the implementation of big data analytics is discussed in the literature, it follows a rather conclusive approach without much focus on the potential for further development [43], [48], [49], which was also observed in the course of the literature review. The necessary tools and technologies are chosen, combined and as a result, a finished analytical system emerges. Ideally, along the way or at least at the end, there also occurs some testing, showing that the solution does what it is supposed to do. Subsequently, the system is used and hopefully generates valuable insights. During the conducted interviews, it was also stated by expert 1 that this habit is not uncommon amongst companies.

While it sounds like an expedient approach and also is in many situations, it also disregards the demands that arise for other businesses. As long as only the sensors of a factory are being monitored, a system can remain the same and deliver the desired information for a long time. However, when it is applied in a dynamic situation, its degradation starts immediately and the obtained results and therefore also the corresponding benefits are being negatively affected [50]. Furthermore, as pointed out by expert 1, depending on the organizations line of work, external factors like statutory rules can result in huge fines if they are not taken care of in time. The same reduction of value occurs when the company itself evolves, leading to new questions that need to be answered in order to enhance the business [51]. This also requires to make changes to the existing system or the implementation of a new one.

Using the aforementioned dimensions, the degree of stability, respectively dynamism that applies to an organization can be determined via a survey as depicted in Figure 4. Since 7-point, 9-point and 10-point scales generally yield the best results [41] and the determination of the positioning regarding the assessed factors being rather imprecise, using a linear scale on the lower end of that spectrum appears to be the most promising approach to achieve the highest degree of certainty.

To easily determine the position of an examined organization on the spectrum between stable and dynamic, it appears to be sensible to provide an index that condenses the evaluations regarding the six identified dimensions to a single value. This would result in a Likert scale [52], comprising the values from 6 to 42. However, since it was to assume that the dimensions are not all equally impactful for this evaluation, it was deemed reasonable to accommodate this factor. For this purpose, the interviewed experts have each been asked to rate the importance of those factors regarding the overall evaluation, again using a linear scale, this time ranging from 1 (lowest) to 10 (highest), allowing for more differentiation between the answers. Thereupon, the responses have been combined and the respective dimension's influences determined by adding all the assigned values across the dimension and dividing it by the sum of all the assigned values 
across all dimensions. The results, signifying the relative importance of the aspects, are depicted in Figure 5.

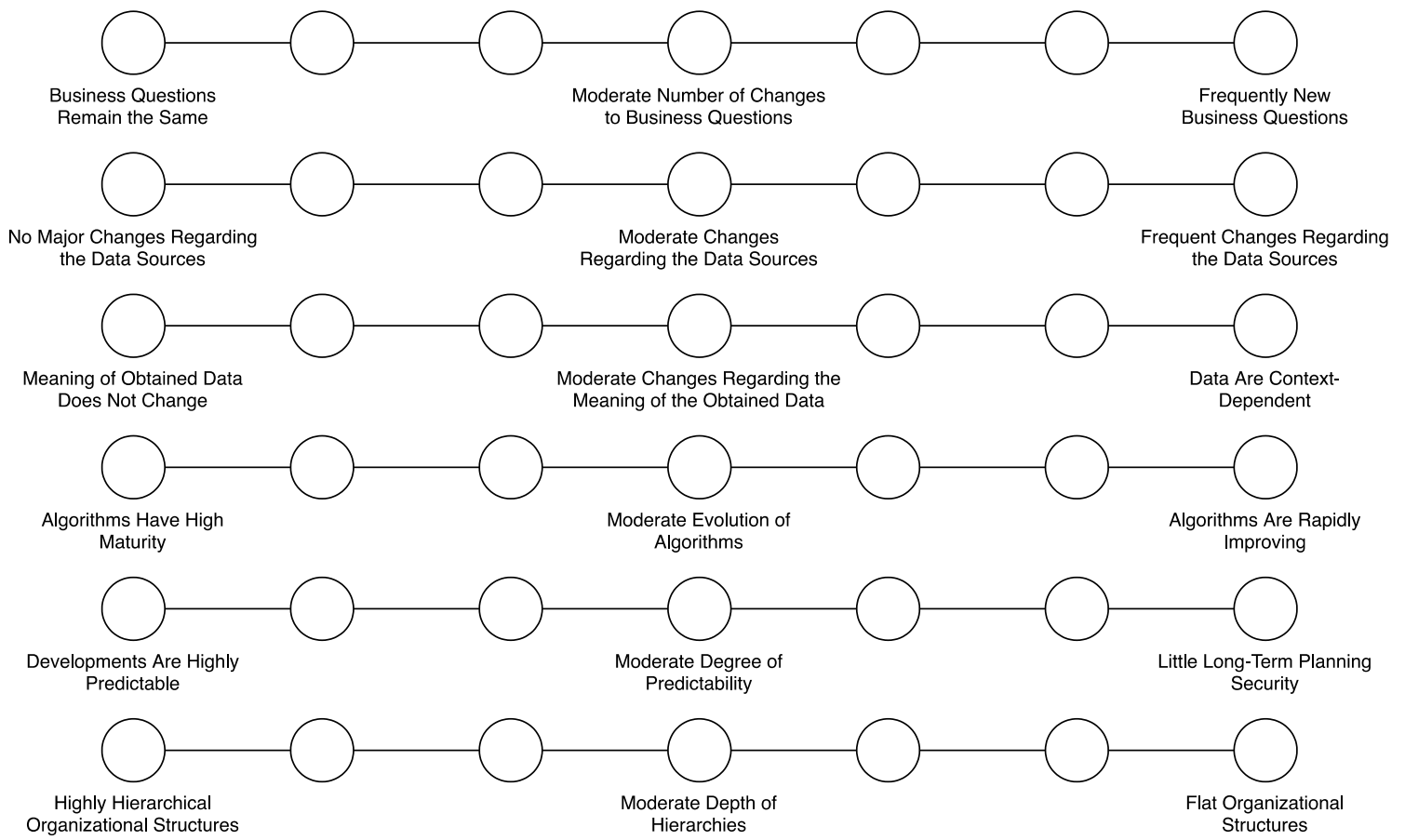

Figure 4. Survey to determine the degree of stability and dynamism

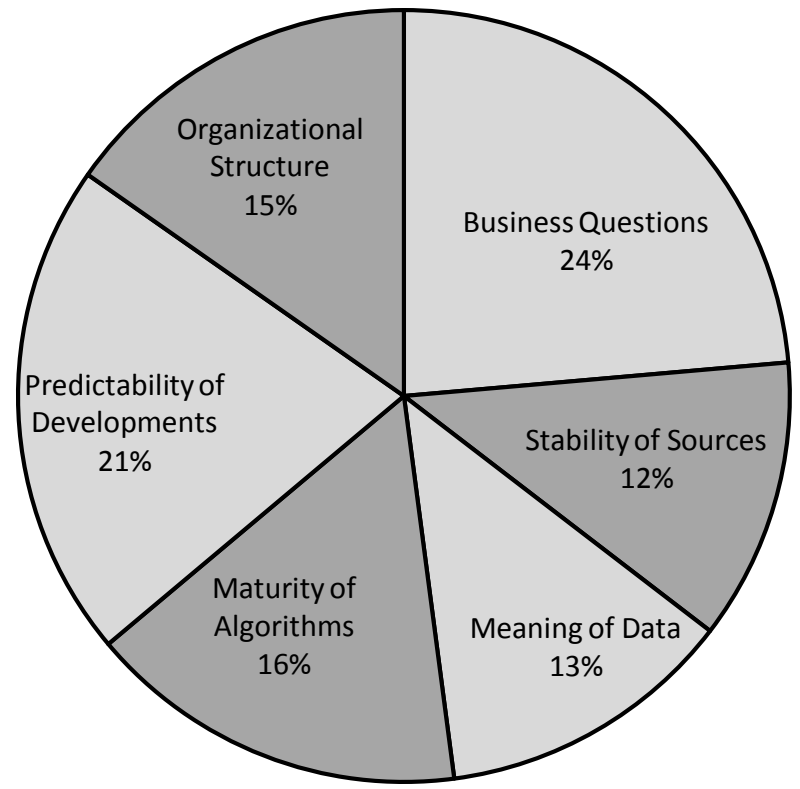

Figure 5. Impact of the identified dimensions on the dynamism index

Those weightings can subsequently be used in conjunction with the organization's evaluation regarding those dimensions to calculate the one-dimensional index. For this purpose, the values stemming from the evaluation are multiplied with their corresponding impact, and then summed up, leading to a value between 1 and 7 that takes the dimensions varying impact into account, allowing for a more precise assessment. 


\subsection{Consequences of Rapidly Evolving Business Environments}

This subsection at first deals with the main results of the previously described structured literature review, which shows that the four Vs of big data (cf. Figure 1) can be divided into two categories, namely predictable and unforeseeable ones. Due to their distinct influences on dynamic business environments, those will be further investigated and described in the given context. In Subsubsection 3.2.1, predictable consequences of dynamic business environments, in terms of volume and velocity, are discussed. Afterwards, in Subsubsection 3.2.2, the same is done for unforeseeable consequences of dynamic business environments, which might be caused by changes in variety and veracity. Subsequently, using those findings and the conducted expert interviews, the effects of dynamic business environments on big data analytics solutions are discussed in Subsubsection 3.2.3.

\subsubsection{Predictable Consequences of Dynamic Business Environments in the Literature}

With the success and further emerging of big data analytics [53], businesses strive to accumulate more and more data in order to generate more and more knowledge about their customers preferences [54], [55] and how better marketing strategies can be developed. Thus, the volume of big data will predictably increase and more powerful solutions will be needed. The performance of the processing systems becomes an even bigger issues if the data is time-sensitive or if the success of whatever the data is used for depends on an immediate analysis. These data streams, which vary in volume and velocity and require a continuous processing, are, for instance, of importance in stock markets [56] and the tactical domain [57]. Especially in these fields of application, the focus is less on solely descriptive or predictive analyses, but rather the acquisition of prescriptive knowledge [58]. This means an answer to the question "What should I do?" is more important than an answer to "What happened before and what could possibly happen next?". While companies and other users of big data analytics are aware of these upcoming issues, the search for solutions which cover their specific needs intensifies. Multiple approaches, including cloud, fog and edge computing [55], [59], gain interest in this regard. However, the processing capacities of the systems are not the only factor to consider when it comes to time-sensitive data. In a dynamic environment with distributed data sources, inter alia, the network capability might become the decisive bottleneck if a centralized approach is adopted [55]. To prevent the system from losing its value for the company due to bandwidth fluctuations [56], fog computing, in contrast to cloud computing, distributes the processing of big data at the edges of the network.

Darwish and Abu Bakar [55] conducted a case study that investigates, how the dynamic environment of Intelligent Transport Systems (ITS) benefits from research in the big data area. Especially since the participants of the ITS domain can be compared to devices in the Internet of Things, the research area of the study shows certain parallels to a business environment. The authors found that only fog computing provides the necessary performance, because in traffic, it is not assured that a stable network connection can be provided at any time. Moreover, since every vehicle in an ITS can produce new data primarily when it is actively used, the actual number of data sources is highly variable. To address the issue of scalability, processing capacities would increase dynamically if the sources themselves would preprocess their own accumulated data. In this context, fog or edge computing might seem to be more suitable solutions than cloud computing. For the fact that only the volume and velocity of data is considered in this explicit case, the more complex future challenges of unforeseeable dynamics in variety and veracity need to be examined separately in the Subsubsection 3.2.2.

Two consequences for big data analytics applying companies arise from the previous observations on dynamic environments. First, to be able to provide a reasonably priced as well as highly performant solution, businesses need to take advantage of the possibilities of the Internet of Things domain [58] by including the data generating devices into the processing. Thus, dynamics in volume and velocity can be immediately handled by proportionally increasing processing capabilities. Secondly, the complexity of the data needs to be reduced in order to 
decrease the workload and used bandwidth. Lin et al. [53] argue that machine learning approaches in particular can provide valuable solutions for abstraction and dimension reduction. As a pre-processing task, important features of the data can be identified and with this simplification the efficiency and accuracy of dynamic analysis of large data sets can be increased. The use of artificial intelligence is further described in the Subsubsection 3.2.1.

\subsubsection{Unforeseeable Consequences of Dynamic Business Environments in the Literature}

Variety and veracity, in turn, are the dimensions of big data in dynamic environments which are less predictable than the increase in volume and velocity. While some researchers argue, that the acquired data is always structured in some way [55], others are more reserved in making such an assertion [59]. Because of the growing interest in numerous domains from which large amounts of data might be received, beginning with data on the production process up to recommendations based on user experience [60], researchers and practitioners are confronted with the need to handle upcoming new data structures as soon as they emerge. While it can be assumed that with increasing volume new data structures occur more frequently, the structures themselves might be unpredictable. Also, the veracity of the data can suffer from the fact that new data structures without sufficient test runs have unknown potential for interference due to their dynamic appearance. Another major difficulty are redundancies. Multiple data sources do not guaranty that every piece of data is unique, which means that the quality of a subsequent analysis is lower than expected [61].

One way to address this problem according to researchers is the enactment of artificial intelligence [53], [58], [62]. Generally, the objective is to develop a software solution which, after an initial training phase, is capable of self-configuration and fine tuning without human intervention [53]. This approach offers benefits in various stages of big data analytics. For instance, in the preprocessing phase, the abstraction and thus simplification, as well as the extraction of features and the removal of noise [62] and unneeded attributes by intelligent systems can lower the workload and thereby improve the performance [53]. Due to the fact that both, knowledge in the problem domain as well as in the technology landscape [63], are required to adjust a big data analytics system in a specific scenario, the time consumption for the entire development team would dynamically increase with the upcoming of new data structures. At some point, human workforce would not be capable of integrating new tailored algorithmic solutions as quickly as new requirements arise. Since the self-configuration of prescriptive analytics models is a largely unexplored field of research [58], businesses need to strive further to develop and test such technologies to get an edge over their competitors.

Various consequences as a result of rapidly evolving dynamic business environments can be derived from the studies found. However, none of the publications offers a comprehensive overview of all possible challenges as well as opportunities for a particular scenario in terms of volume, velocity, variety and veracity. Case studies in customer-oriented businesses [54, 62], the tactical domain [57], healthcare [61, 64] and transportation [55] differ in their proposals on how software solutions have to be developed to meet predictable and unpredictable future requirements, in order for the analysis of the data to fulfil the meaning of an additional big data characteristic, the value [54].

\subsubsection{Big Data Analytics Solutions in Dynamic Business Environments}

As it was exhibited in the literature review and is also validated by quantitative studies [13] and the conducted expert interviews, BDA can provide significant advantages to a business. Though, the practical incorporation is generally accompanied by many obstacles [22] and this especially applies to highly dynamic business environments, which pose additional challenges, since they require the analysis solution to be constantly adjusted regarding the new circumstances [9], [61]. However, doing so can be a costly endeavor. This comprises, inter alia, the costs for licenses, access to additional data sources, administration, acquisition and operation of hardware or the booking of cloud services. Those financial expenditures were also autonomously brought up by the experts, highlighting their seriousness to practitioners. Even though there are numerous open 
source solutions that are free to use, this can be deceiving regarding the costs that have to be expected, since it is still necessary to ensure the proper implementation and adaptation for the desired use case. Considering the complexity of many big data analytics systems, this often requires the knowledge of highly demanded, and therefore expensive, experts [65]. Yet, if those alterations of the system are not realized, the corresponding expenses are saved, but the alignment of the analytics capabilities and the business needs is reduced [54]. While that might be unavoidable to a certain degree, at some point, the purpose of the system is not met any longer, since the benefit through the provision of superior information is diminished too much. At that point, the system should be modified or decommissioned and potentially replaced by a new one, since an inadequate analytics application can even result in a negative benefit, when based on its outputs, either wrong decisions are made or good opportunities are not seized because they are overseen by the system and it is relied on too heavily [66]. Consequently, by taking all of the aforementioned implications from the previous lines of argumentation, the SLR and the expert interviews into account, numerous considerations need to be made when it comes to the application of BDA in dynamic business environments. An overview of those previously discussed factors is depicted in Table 5.

Table 5. Implications of dynamic business environments on BDA

\begin{tabular}{|c|c|}
\hline Name & Description \\
\hline $\begin{array}{c}\text { Data Context } \\
\text { Changes }\end{array}$ & $\begin{array}{l}\text { Inaccuracies of the data analysis due to changes of the data context may occur. Even though the } \\
\text { recipient at the time can be aware of the initial intention, the context may change in the future, } \\
\text { which in turn may result in extensive and time-consuming changes of the analysis, as they were } \\
\text { exemplarily indicated for the case of Corona. }\end{array}$ \\
\hline $\begin{array}{c}\text { Data Source } \\
\text { Changes }\end{array}$ & $\begin{array}{l}\text { Data sources may constantly changes, not only in terms of the data provision in general but also } \\
\text { regarding its particular quality, content, technical implementation, used language and others. } \\
\text { Therefore, it can be necessary to adapt the integration of already harnessed sources, or to even } \\
\text { stop using them, as well as to incorporate new ones. }\end{array}$ \\
\hline $\begin{array}{c}\text { Varying System } \\
\text { Load }\end{array}$ & $\begin{array}{l}\text { The system load can be extremely dependent on external circumstances, which can lead to highly } \\
\text { heterogeneous demands when comparing different points in time. However, generally, the } \\
\text { volume of the data is continuously increasing, independent from its intended purpose. As a } \\
\text { consequence sophisticated considerations are required, in order to find suitable solutions that } \\
\text { might be capable in the future. }\end{array}$ \\
\hline $\begin{array}{l}\text { Changing } \\
\text { Bottlenecks }\end{array}$ & $\begin{array}{l}\text { Although the processing capabilities of a solution in dynamic environments might be able to } \\
\text { overcome current demand, bottlenecks can be still a source of errors. Possible causes, such as } \\
\text { network issues, should be taken into account when it comes to the planning and realization. This } \\
\text { is aggravated by the fact that the bottleneck might change depending on external circumstances } \\
\text { and the corresponding need for the system's adaptation. }\end{array}$ \\
\hline $\begin{array}{c}\text { Data Structure } \\
\text { Changes }\end{array}$ & $\begin{array}{l}\text { Through the additional extension and alterations of the original data sources, changes of the data } \\
\text { structure may appear. Consequentially, the system planning should take those upcoming } \\
\text { modifications into account. }\end{array}$ \\
\hline $\begin{array}{c}\text { Lack of } \\
\text { Trustworthiness }\end{array}$ & $\begin{array}{l}\text { Due to the inclusion of new data sources as well as the evolution of already utilized ones, it is } \\
\text { necessary to constantly monitor the trustworthiness of the obtained data. Therefore, additional } \\
\text { analysis might be required to assess and increase the overall veracity of the data. }\end{array}$ \\
\hline $\begin{array}{c}\text { Data } \\
\text { Redundancy }\end{array}$ & $\begin{array}{l}\text { As a consequence of the massive data collection, management and processing, meticulous } \\
\text { monitoring is needed. This applies not only to the data but also the sources, preventing possible } \\
\text { fallacies through duplicated data, which might falsify the results of the analysis. }\end{array}$ \\
\hline
\end{tabular}

Concluding those considerations, we define dynamic business environments in big data as settings that are characterized by a constant change of external circumstances, internal requirements and technical capabilities, leading to the need for continuous adjustments and modifications of the logic and implementation of the BDA solutions incorporated into a business' digital infrastructure.

In Figure 6, a structured approach, which was also agreed to by all of the questioned experts, both, regarding the necessity as well as the concrete design, is depicted, systematizing that decision making. The different states that are being traversed throughout the lifespan of such a system are depicted, not explicitly mentioning its actual use. In the beginning, the new big data 
analytics solution is initially implemented. Afterwards, unless it is decided that its general purpose has ceased to exist, the system is supposed to always be active, making its mentioning superfluous. Ideally, at the point of initial implementation, a BDA application's alignment with the actual business needs is extremely high, allowing for high quality analysis and providing valuable insights that enrich the company and its decision making process. However, due to the nature of the regarded domain, changes are bound to happen, resulting in a need for thorough monitoring. The nature of those changes can be manifold, including but not being limited to the emergence of new business needs, the creation of new algorithms and techniques or changes regarding the available sources. While some of those changes are apparent (e.g. when new business questions cannot be sufficiently answered), others, like the slow decline of a news paper's quality, might be harder to determine. Therefore, this endeavor is already a challenging task on its own. Yet, not every change that is perceived, is necessarily relevant. Some might be immediately discarded for various reasons [53]. For those that are not, subsequently, the potential reactions have to be assessed. This includes the analysis of the change and its effects on the value of the system, the exploration of options as well as the forecast of benefits and costs of those options. On a high level, there are four potential ways of reacting to a change. The use of the system can be continued as usual, its replacement can be decided, it can be decommissioned without any substitution or it can be modified. The latter could, for instance, include the implementation of enhanced algorithms or the incorporation of new sources. If the solution as a whole is to be replaced, it is common to prepare the new one, while the current one is still in use, allowing for a seamless transition with as little downtime as possible, once the new system is ready for use [67]. In any case, except for the discontinuation of the BDA, the monitoring continues, letting the cycle begin again.

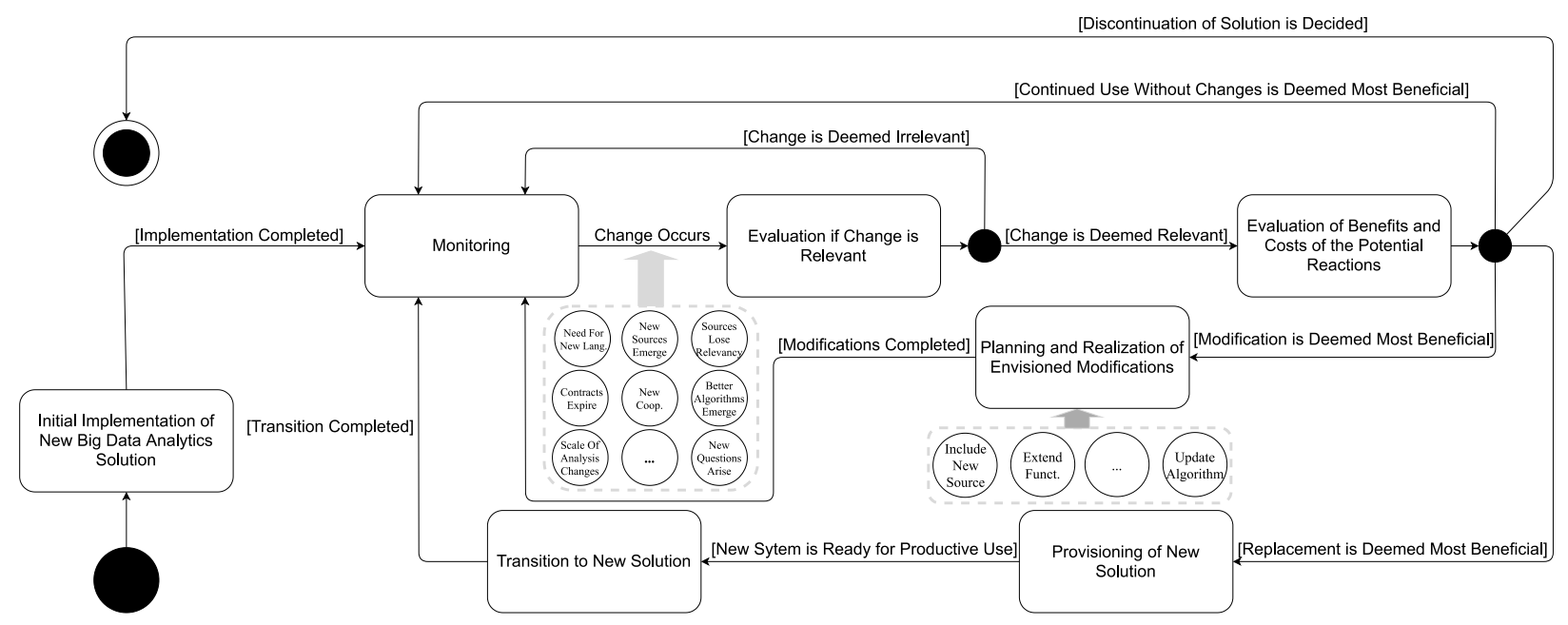

Figure 6. States of a big data analytics solution in a dynamic business environment

\section{Possible Measures to Cope With Dynamic Business Environments in the BDA Domain}

As the result of the above considerations that are outlined in Figure 6, companies, and particularly those in dynamic business environments, face three major tasks regarding that aspect. The first one is to identify relevant changes, being a prerequisite for an adequate reaction. The second task is to determine as precisely as possible, when it is beneficial to invest into the revision of an existing system and to which extend or if it should even be completely replaced, respectively abolished. The third one is to increase the longevity of the systems that are being implemented as well as to reduce the costs for performing necessary adaptions. 


\subsection{Evaluation of the Available Options}

The first two previously deduced tasks, identifying the relevant changes in the business environment and evaluating the potential reactions to those changes, are both to be constantly conducted, allowing a company to base its decisions regarding its BDA solution on reliable information. While some of the changes are apparent, others might require more efforts to be spotted, which was also highlighted during the interviews. Some of those measures could include the monitoring of relevant technical conferences to get a grasp of new developments regarding the relevant algorithms, a structured process to evaluate potential data sources or, as one of the experts pointed out during the interviews, regular surveys of the employees, to discover their needs and requests. Yet, not every change or request is relevant, therefore, besides the mere gathering, there also should be standardized processes to facilitate the according categorization. That way, the big picture can be taken into consideration and those decisions are less likely based on random factors (e.g. who discovered the change), which an interviewee mentioned as a potential risk, when there are no structured processes in place. However, the specific design of those processes might highly vary, depending on the organization and system under consideration.

Once such a change was noticed and deemed relevant, there are four general options, as depicted in Figure 6. To facilitate the according decision making, a structured process is necessary, as it was agreed to by the interviewed experts. The diagram in Figure 7 shows such a process, specifying the steps from the registration of a new relevant change to the final decision on a course of action. While its foundation is for the most part based on established change management strategies from the IT realm [68], [69], the concrete design incorporates the specific needs of the regarded domain as well as the possible courses of action, indicated in Figure 6.

In the beginning, the new change is analysed to create a preliminary list of aspects it may potentially affect. Subsequently, the concrete effects of the change are determined and evaluated, resulting in its thorough analysis.

Then, it is incorporated into the existing list of changes that have not yet been acted on. This list stems from previous iterations of this process and can also be empty. Any obsolete entries are removed from this combined list, resulting in an updated list of changes that is used in the further process but is also an input for future iterations. Afterwards, the determined effects of all remaining changes are aggregated, to get an overview. Now, the earnings and savings through the continued use of the current solution are forecasted, taking into account the effects the changes have on its provided gains. Moreover, also the corresponding costs for its operation are assessed, allowing to quantify the solutions benefits and concluding its evaluation. Those first nine activities of Figure 7 could be labelled as gaining an understanding of the status quo.

This is followed by the evaluation of two options: on the one hand, the modification of the existing solution and, on the other hand, its replacement with a new system. Those tasks can either be handled sequentially in an arbitrary order, or in parallel, depending on the available resources, with the latter allowing for a faster completion of the decision making process.

To achieve the assessment of the option of a modification, at first, the previously compiled list of changes is walked through, determining potential adjustments to react to each of the entries. The adjustments are then each analysed regarding their benefits and costs, with the former being compared to the current state of the system. Thereupon, the most beneficial set of adjustments is determined and the expected earnings and savings, as well as the expected costs for implementing the adjustments and operating the modified solution are calculated, resulting in the evaluation of the most beneficial modified solution. 


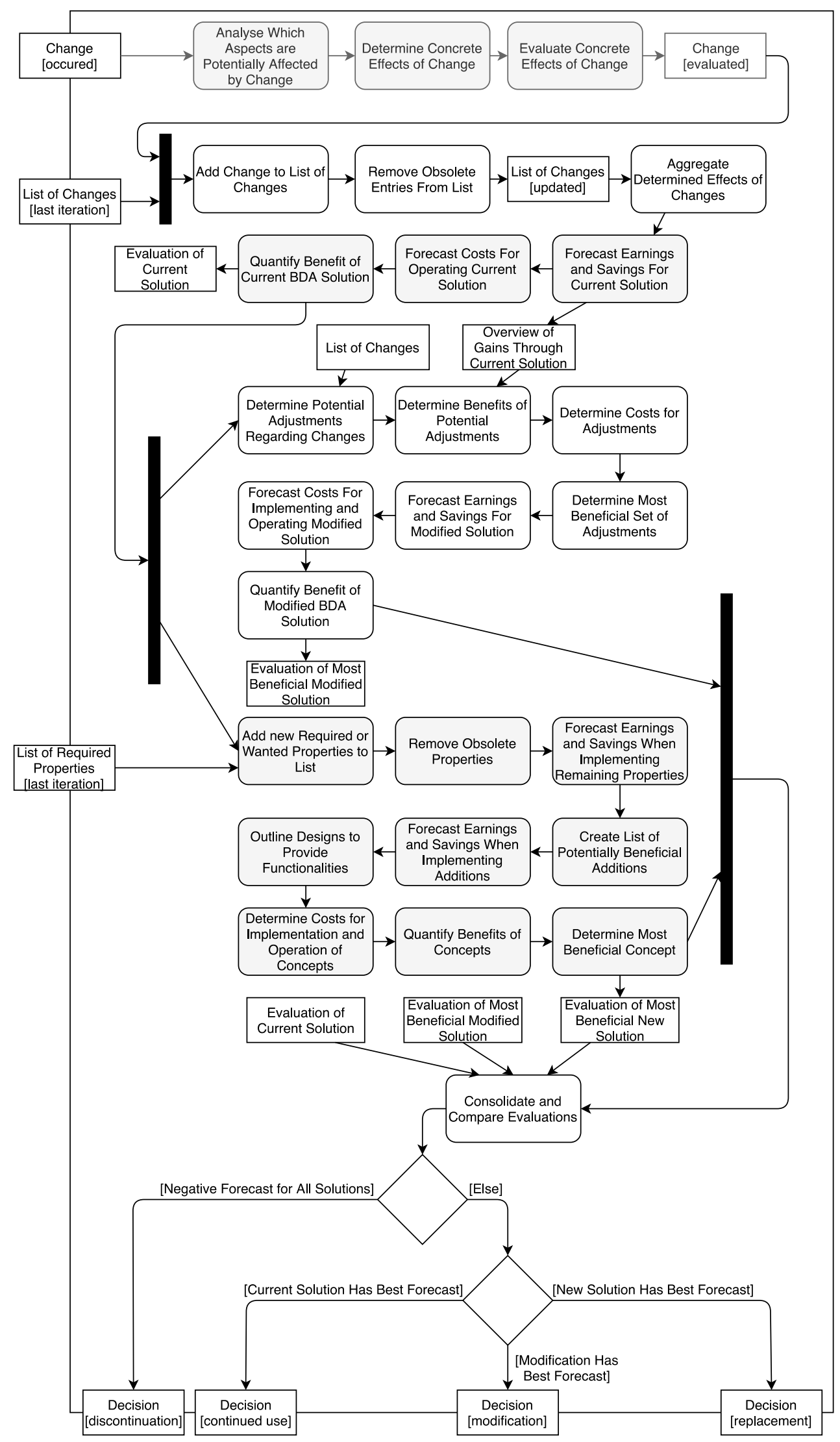

Figure 7. Determining the reaction to the occurrence of a relevant change

Regarding the evaluation of the potential development of a replacement, similar to the list of changes, a list of requirements and wished for aspects is consulted. This list is amended with new entries that might have become apparent since the last iteration of this process. Properties that have become obsolete are removed, and for the remaining set, a forecast of the expected 
earnings and savings is conducted. Ensuing, a list of potentially beneficial additions to those mandatory specifications is created. The different combinations of basic features and extensions are then regarded, concerning the expected gains. Subsequently, concepts for the concrete implementations of those variants are prepared and the resulting costs for implementation and operation determined. Combining the benefits and costs, the most beneficial concept for the development of a new solution is identified.

Once the most beneficial modification as well as the most beneficial concept for a replacement are evaluated, those findings are compared with the analysis of the currently used solution and the final decision is made according to the results. If the three options (continued use, modification, replacement) each have a negative forecast, the system should be discontinued, otherwise, the one with the best expected result is to be pursued.

This recommendation regarding the most favourable course of action is also the output of the described process, after undergoing all the phases from gaining an understanding of the status quo, over assessment of the option of a modification and evaluation of the potential development of a replacement, culminating in the final decision.

While the general process was agreed to by the interviewed experts, it was also pointed out that it is rather high-level, necessitating more specifications for the implementation in concrete organizations. This mainly relates to the evaluation of costs and benefits, which is, however, highly specific and therefore out of the presented process' scope.

Asked for the most common mistakes, the interviewed experts especially stressed that the costs and duration for conducting implementations are often underestimated. Potential causes that were mentioned are a bias towards new solutions, influencing the evaluation, a gap between those making the decisions and estimations and those that are putting the concepts into practice, as well as the general complexity of the regarded systems that make it hard to grasp all dependencies. Furthermore, the oversimplification of the problem, respectively the attempt of taking shortcuts, the drawing of premature conclusions from limited data, the general difficulty of mapping effects and causes in complex systems and also the insufficient involvement of all relevant stakeholders, which is also in correspondence with [50], were mentioned. An overview of those identified common mistakes is depicted in Figure 8.

While some of those issues are due to the nature of the task and therefore unavoidable, others can be solved or mitigated by raising awareness and the implementation of structured processes. However, when not properly dealing with them, organizations risk to make decision which are not optimal or even plain wrong. This in turn can result in very expensive mistakes, which could potentially be detrimental to the organization's future or at least hamper its success.

\subsection{Facilitating the Modifiability of BDA Solutions}

While the interviewed experts acknowledged the importance of the decision making process, three out of four considered the improvement of the modifiability of an existing or envisioned BDA solution more important. Asked for their proposed approaches to accomplish this goal, there was a variety of answers given. Those include the definition of and adherence to standards, helping to uphold the quality, the use of agile development approaches and also the necessity for support by the management and organizational accommodations were stressed, which is also in concordance with the literature [10]. Besides those rather organizational aspects, it was also emphasized that the mindset and qualification of the architects and developers plays a crucial role, since more capable ones often produce more generic solutions instead of achieving the bare minimum to just fulfil the current needs. 


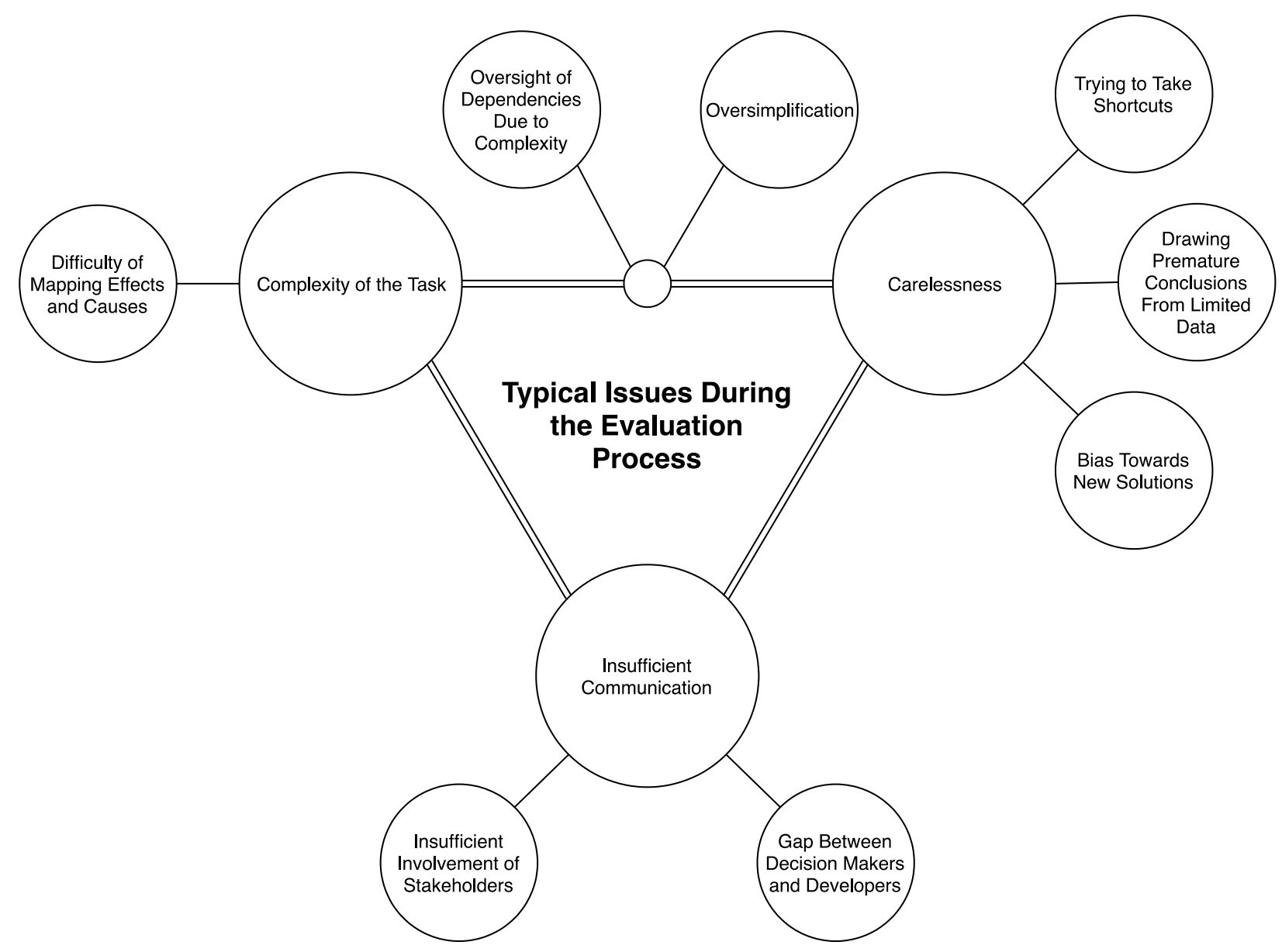

Figure 8. A list of typical issues during the evaluation process

Furthermore, according to the interviews, the application of a compartmentalized design concept appears to be a promising solution for the reduction of costs for a BDA solution's modification. In conjunction with a corresponding test strategy, the components would be mostly independent, allowing for a comparatively easy modification or replacement, since not the system as a whole but only a confined part would be affected. This in turn would highly reduce the complexity and therefore the corresponding costs as well as the development time, which allows for a more frequent alignment of the analytics capabilities with the actual business needs.

Dynamic environments require dynamic solutions, which means, that a software artefact needs the capability to be as quickly adjusted as variations in the field of application arise. A long time, so-called monoliths as single executable systems, with shared resources among the interdependent modules, were the primary approach in the software industry [70]. However, as the systems grow, the complexity and the effort for maintenance can increase to an unknown level [71]. Especially when changes are demanded very frequently, this approach turns out to be undesirable. Any change requires the rebooting of the application, which leads to significant downtimes [70] while the value of data might decrease in this phase and the desired benefits of the system cannot be obtained. Figure 9 proposes, apart from the monolithic approach, how a big data analytics system can be organized, delineating two granularities of compartmentalization. The layered architecture divides the system among its logical purposes: data acquisition, storage, analysis and output. However, this varies only slightly from a monolith due to the fact, that even these separated domains can increase in complexity. For instance, if new data sources are to be included in the analysis process, every layer needs to implement new functionalities to handle the deviating structures.

A further step towards achieving actual modularity and an extremely high degree of flexibility could be taken with the integration of a microservice architecture, where a microservice 
"provides a business or platform capability through a well-defined API, data contract, and configuration" [71], meaning that it has only one single function and "does it well" [71]. While the reusability of the individual services for several BDA solutions helps to reduce redundancies and thus development costs, this approach also enables high scalability, since each service can be started multiple times in parallel over several instances. In combination with a suitable test strategy, which might resemble the modular approach proposed in [72], a desired BDA solution can be assembled from a variety of microservices.

As a result, those microservice architectures were not only mentioned as a promising approach in the course of the interviews, but also gain interest from academics and practitioners [73]. These services are described as autonomous and isolated pieces of software, which means that they are designed, developed, tested and deployed independently and have only one small purpose each [63], [71]. Accordingly, the individual components are equipped with dedicated tools with optimum suitability [70]. This includes the possibility of using distinct programming languages for different services, allowing the most appropriate frameworks to be utilized for each purpose [63]. In contrast to the monolithic approach, microservice architectures let the designed solutions evolve dynamically alongside the general purpose of the big data analytics system. For instance, if new data sources arise, the only task of the development department is to integrate the capabilities to acquire data from that specific source. While more and more functionalities can be provided over time [73], the use of the system has value as soon as a first chain of logically coupled microservices is integrated [71]. As a consequence, businesses in rapidly evolving dynamic areas might profit from integrating microservice architectures to get an edge over their competitors when the conditions for business success are tied to the fast processing and integration of new data respectively new data sources. The example in Figure 9 shows how a microservice architecture can be implemented in big data analytics. As recommended by [63] for larger applications, an API gateway is used as an entry point from the client side to distribute user requests to the appropriate services. In the figure, the services are organized in logical domains based on the layers in the layer architecture. Depending on the specific BDA solution, the domains can be further extended with a load balancer or other intermediate extensions to support scalability and performance. In addition, some services may be interconnected if their functionalities depend on other services.
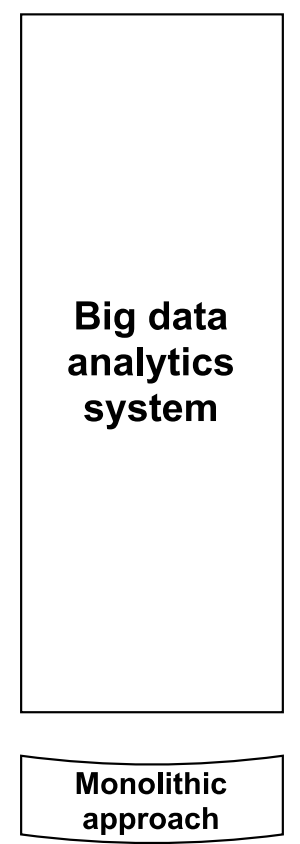
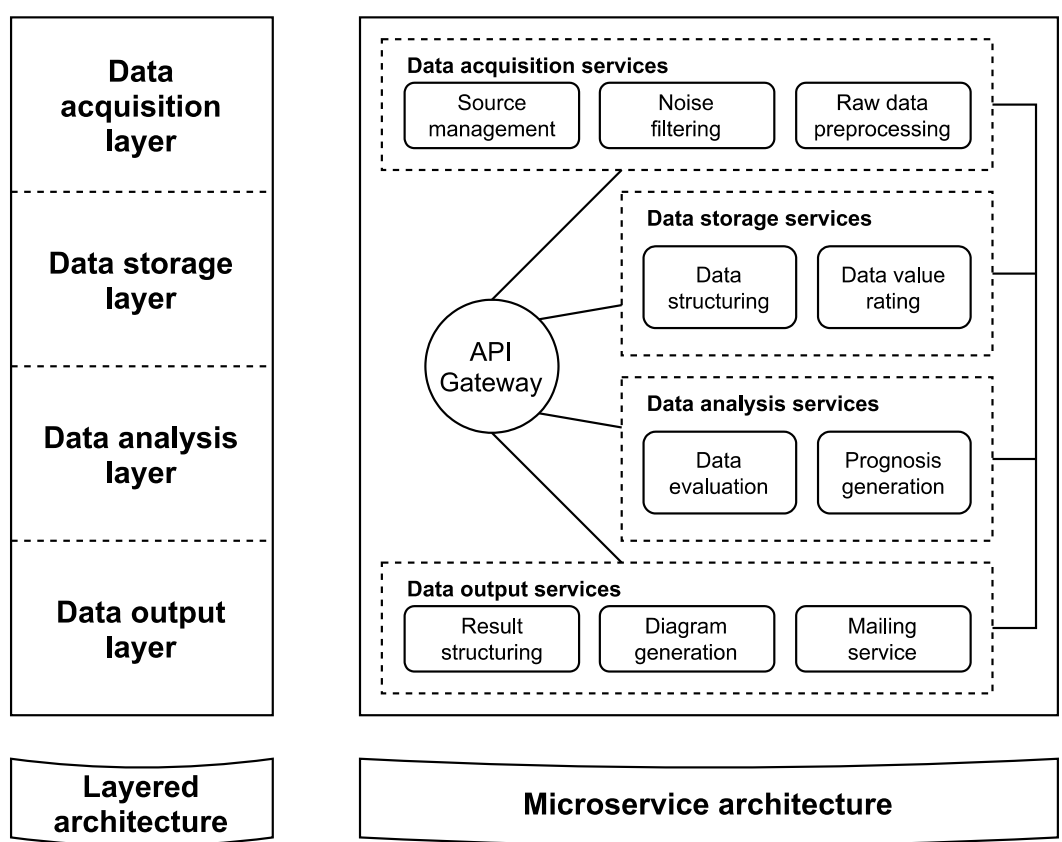

Figure 9. Illustrative division of a monolithic BDA solution into microservices 


\section{Concluding Remarks}

Big data is a highly prominent area amongst both, researchers and practitioners. However, while there are numerous publications regarding the general topic, the implications of an implementation in a highly dynamic business environment are not adequately researched. Yet, businesses that are reliant on highly volatile data sources or frequently change their business questions, respectively the specifics of their analytics, face particular challenges that surpass those of less dynamically positioned companies. This article sheds light on the situation of those former ones, the consequences regarding the alignment between business and IT and deduces the challenges that arise. Resulting out of this, the current impact of dynamic business environments on big data analytics was thoroughly investigated and visually illustrated. Additionally, expert interviews as well as a structured literature review were carried out that approve and extend current problematics. Beyond that, possible counter measures are explained in a detailed way, intending to overcome the paucity of existing solutions of this particular research problem. Eventually, future works can build on those findings and therefore help to improve the alignment between business needs and the IT, even in highly demanding situation.

However, as one may note, this article is subject to certain limitations, predominantly applying to the conducted expert interviews. A total of four different experts were interviewed, who together possess over 60 years of work experience in the IT domain. Although this is a sufficient number of respondents to get a solid overview, for numerical evaluations the overall sample is rather small. Therefore, the results of the extensively conducted interviews cannot be fully transferred to a larger group. Nevertheless, all respondents were able to confirm the initial suspected problems and additionally added further insights. This in turn influenced the described concepts, even though no major changes were deemed necessary by the experts.

Nevertheless, for the future it is planned to implement the proposed concepts and to conduct the interviews again on a larger scale. In doing so, innovations and concepts that appeared to be promising can be further investigated, leading to further insights. This primarily concerns the modularization of big data system architectures through the use of microservices. With the help of those, it can be expected in the future that dynamic changes such as those that occur extensively in today's dynamic business environments can be coped with in a more effective manner.

\section{References}

[1] M. Chen, S. Mao, and Y. Liu, "Big Data: A Survey," Mobile Networks and Applications, vol. 19, pp. 171-209, 2014. Available: https://doi.org/10.1007/s11036-013-0489-0

[2] S. Ghemawat, H. Gobioff, and S.-T. Leung, "The Google File System," Proceedings of the nineteenth ACM symposium on Operating systems principles, ACM SIGOPS Operating Systems Review, ACM, vol. 37, no. 5, pp. 29-43, 2003. Available: https://doi.org/10.1145/945445.945450

[3] K. Nagorny, P. Lima-Monteiro, J. Barata, and A. W. Colombo, "Big Data Analysis in Smart Manufacturing: A Review," International Journal of Communications, Network and System Sciences, vol. 10, no. 3, pp. 31-58, 2017. Available: https://doi.org/10.4236/ijcns.2017.103003

[4] L. Zhu, F. R. Yu, Y. Wang, B. Ning, and T. Tang, "Big Data Analytics in Intelligent Transportation Systems: A Survey," IEEE Transactions on Intelligent Transportation Systems, vol. 20, no. 1, pp. 383-398, 2019. Available: https://doi.org/10.1109/TITS.2018.2815678

[5] T. Nguyen, L. Zhou, V. Spiegler, P. Ieromonachou, and Y. Lin, "Big Data Analytics in Supply Chain Management: A State-of-the-Art Literature Review," Computers \& Operations Research, vol. 98, pp. 254264, 2018. Available: https://doi.org/10.1016/j.cor.2017.07.004

[6] K. Fanning and E. Drogt, "Big Data: New Opportunities for M\&A," The Journal of Corporate Accounting \& Finance, vol. 25, no. 2, pp. 27-34, 2014. Available: https://doi.org/10.1002/jcaf.21919

[7] Y. Hu, D. Gal, and Y. Hong, "Modeling Brand Personality with Business Value of Social Media Analytics: Predicting Brand Personality with User-generated Content and Firm-generated Content," Proceedings of the 39th ICIS, 2018. 
[8] P. Maroufkhani, R. Wagner, W. K. Wan Ismail, M. B. Baroto, and M. Nourani, "Big Data Analytics and Firm Performance: A Systematic Review," Information, vol. 10, no. 7, article 226, 2019. Available: https://doi.org/10.3390/info10070226

[9] S. F. Wamba, A. Gunasekaran, S. Akter, S. J.-F. Ren, R. Dubey, and S. J. Childe, "Big Data Analytics and Firm Performance: Effects of Dynamic Capabilities," Journal of Business Research, vol. 70, pp. 356-365, 2017. Available: https://doi.org/10.1016/j.jbusres.2016.08.009

[10] P. Mikalef, M. Boura, G. Lekakos, and J. Krogstie, "Big Data Analytics and Firm Performance: Findings from a Mixed-Method Approach," Journal of Business Research, vol. 98, pp. 261-276, 2019. Available: https://doi.org/10.1016/j.jbusres.2019.01.044

[11] A. Ferraris, A. Mazzoleni, A. Devalle, and J. Couturier, "Big Data Analytics Capabilities and Knowledge Management: Impact on Firm Performance,” Management Decision, vol. 57, no. 8, pp. 1923-1936, 2019. Available: https://doi.org/10.1108/MD-07-2018-0825

[12] E. Raguseo and C. Vitari, "Investments in Big Data Analytics and Firm Performance: An Empirical Investigation of Direct and Mediating Effects," International Journal of Production Research, vol. 56, pp. 5206-5221, 2018. Available: https://doi.org/10.1080/00207543.2018.1427900

[13] O. Müller, M. Fay, and J. vom Brocke, "The Effect of Big Data and Analytics on Firm Performance: An Econometric Analysis Considering Industry Characteristics," Journal of Management Information Systems, vol. 35, pp. 488-509, 2018. Available: https://doi.org/10.1080/07421222.2018.1451955

[14] A. Parlina, K. Ramli, and H. Murfi, "Theme Mapping and Bibliometrics Analysis of One Decade of Big Data Research in the Scopus Database," Information, vol. 11, no. 2, article 69, 2020. Available: https://doi.org/10.3390/info11020069

[15] W. L.Chang and N. Grady, NIST Big Data Interoperability Framework: Volume 1, Definitions, Version 3, 2019. Available: https://doi.org/10.6028/NIST.SP.1500-1r2

[16] T. Palpanas, "Knowledge Discovery in Data Warehouses," ACM SIGMOD Record, vol. 29, no. 3, pp. 88-100, 2000. Available: https://doi.org/10.1145/362084.362142

[17] A. Gandomi and M. Haider, "Beyond the Hype: Big Data Concepts, Methods, and Analytics," International Journal of Information Management, vol. 35, no. 2, pp. 137-144, 2015. Available: https://doi.org/10.1016/j.ijinfomgt.2014.10.007

[18] S. Kaisler, F. Armour, J. A. Espinosa, and W. Money, "Big Data: Issues and Challenges Moving Forward," Proceedings of the 46th Hawaii International Conference on System Sciences, IEEE, pp. 995-1004, 2013. Available: https://doi.org/10.1109/HICSS.2013.645

[19] M. Volk, D. Staegemann, and K. Turowski, "Big Data," Handbuch Digitale Wirtschaft, Springer, vol. 58, pp. 1-18, 2020. Available: https://doi.org/10.1007/978-3-658-17345-6_71-1

[20] H. Chen, R. H. L. Chiang, and V. C. Storey, "Business Intelligence and Analytics: From Big Data to Big Impact," MIS Quarterly, vol. 36, no. 4, pp. 1165-1188, 2012. Available: https://doi.org/10.2307/41703503

[21] D. Staegemann, M. Volk, N. Jamous, and K. Turowski, "Understanding Issues in Big Data Applications - A Multidimensional Endeavor," Proceedings of the 25th Americas Conference on Information Systems (AMCIS), 2019.

[22] M. Volk, D. Staegemann, M. Pohl, and K. Turowski, "Challenging Big Data Engineering: Positioning of Current and Future Development," Proceedings of the 4th International Conference on Internet of Things, Big Data and Security, SCITEPRESS - Science and Technology Publications, vol. 1, pp. 351-358, 2019. Available: https://doi.org/10.5220/0007748803510358

[23] A. R. Alaei, S. Becken, and B. Stantic, "Sentiment Analysis in Tourism: Capitalizing on Big Data," Journal of Travel Research, vol. 58, pp. 175-191, 2019. Available: https://doi.org/10.1177/0047287517747753

[24] Y. Lv, Y. Duan, W. Kang, Z. Li, and F.-Y. Wang, "Traffic Flow Prediction with Big Data: A Deep Learning Approach," IEEE Transactions on Intelligent Transportation Systems, vol. 16, no. 2, pp. 865-873, 2014. Available: https://doi.org/10.1109/TITS.2014.2345663

[25] M. Chen, Y. Hao, K. Hwang, L. Wang, and L. Wang, "Disease Prediction by Machine Learning Over Big Data from Healthcare Communities," IEEE Access, vol. 5, pp. 8869-8879, 2017. Available: https://doi.org/10.1109/ACCESS.2017.2694446

[26] Z. Khan and T. Vorley, "Big Data Text Analytics: An Enabler of Knowledge Management," Journal of Knowledge Management, vol. 21, pp. 18-34, 2017. Available: https://doi.org/10.1108/JKM-06-2015-0238

[27] M. Grzegorowski, "Scaling of Complex Calculations over Big Data-Sets," Active Media Technology, Springer, vol. 8610, pp. 73-84, 2014. Available: https://doi.org/10.1007/978-3-319-09912-5_7 
[28] J. vom Brocke, C. Sonnenberg, and A. Simons, "Value-oriented Information Systems Design: The Concept of Potentials Modeling and its Application to Service-oriented Architectures," Business \& Information Systems Engineering, vol. 1, pp. 223-233, 2009. Available: https://doi.org/10.1007/s12599-009-0046-3

[29] K. P. Patten, J. Fjermestad, and B. Whitworth, "How CIOs Use Flexibility to Manage Uncertainty in Dynamic Business Environments," Proceedings of the Fifteenth Americas Conference on Information Systems (AMCIS), 2009.

[30] B. Heesen, "Management Challenges in Dynamic Business Environments," Effective Strategy Execution, Springer, pp. 1-23, 2016. Available: https://doi.org/10.1007/978-3-662-47923-0_1

[31] A. Huang, "A Three-Tier Technology Training Strategy in a Dynamic Business Environment," Journal of Organizational and End User Computing, vol. 14, no. 2, pp. 30-39, 2002. Available: https://doi.org/10.4018/joeuc.2002040103

[32] D. Kim, M. Kim, and H. Kim, "Dynamic Business Process Management Based on Process Change Patterns," 2007 International Conference on Convergence Information Technology (ICCIT2007), IEEE, pp. 1154-1161, 2007. Available: https://doi.org/10.1109/ICCIT.2007.91

[33] M. Dong, C. Wu, and F. Hou, "Shortest Path Based Simulated Annealing Algorithm for Dynamic Facility Layout Problem under Dynamic Business Environment," Expert Systems with Applications, vol. 36, no. 8, pp. 11221-11232, 2009. Available: https://doi.org/10.1016/j.eswa.2009.02.091

[34] L. M. Dyer and C. A. Ross, "Seeking Advice in a Dynamic and Complex Business Environment: Impact on the Success of Small Firms," Journal of Developmental Entrepreneurship, vol. 13, no. 2, pp. 133-149, 2008. Available: https://doi.org/10.1142/S1084946708000892

[35] W. Triaa, L. Gzara, and H. Verjus, “Organizational Agility Key Factors for Dynamic Business Process Management," 2016 IEEE 18th Conference on Business Informatics (CBI), IEEE, pp. 64-73, 2016. Available: https://doi.org/10.1109/CBI.2016.16

[36] D. I. Prajogo, "The Strategic Fit Between Innovation Strategies and Business Environment in Delivering Business Performance," International Journal of Production Economics, vol. 171, part 2, pp. 241-249, 2016. Available: https://doi.org/10.1016/j.ijpe.2015.07.037

[37] J. Luftman, “Assessing Business-IT Alignment Maturity," Communications of the Association for Information Systems, vol. 4, 2000. Available: https://doi.org/10.17705/1CAIS.00414

[38] J. Rowley and F. Slack, “Conducting a Literature Review," Management Research News, vol. 27, no. 6, pp. 31-39, 2004. Available: https://doi.org/10.1108/01409170410784185

[39] C. Okoli, “A Guide to Conducting a Standalone Systematic Literature Review," Communications of the Association for Information Systems, vol. 37, pp. 879-910, $2015 . \quad$ Available: https://doi.org/10.17705/1CAIS.03743

[40] J. Vom Brocke, A. Simons, B. Niehaves, K. Reimer, R. Plattfaut, and A. Cleven, "Reconstructing the Giant. On the Importance of Rigour in Documenting the Literature Search Process," Proceedings of the ECIS 2009, article 161, 2009.

[41] C. C. Preston and A. M. Colman, "Optimal Number of Response Categories in Rating Scales: Reliability, Validity, Discriminating Power, and Respondent Preferences,” Acta Psychologica, vol. 104, no. 1, pp. 1-15, 2000. Available: https://doi.org/10.1016/S0001-6918(99)00050-5

[42] D. Mourtzis, E. Vlachou, and N. Milas, "Industrial Big Data as a Result of IoT Adoption in Manufacturing," Procedia CIRP, vol. 55, pp. 290-295, 2016. Available: https://doi.org/10.1016/j.procir.2016.07.038

[43] A. P. Hassan, "Enhancing Supply Chain Risk Management by Applying Machine Learning to Identify Risks," Business Information Systems, Springer, vol. 354, pp. 191-205, 2019. Available: https://doi.org/10.1007/9783-030-20482-2_16

[44] C. Siebert, J. Hartmann, M. Heitmann, and C. Schamp, “Accuracy of Automated Sentiment Analysis," SSRN Journal, 2019. Available: https://doi.org/10.2139/ssrn.3489963

[45] A. Bruns and J. Burgess, "Twitter Hashtags from Ad Hoc to Calculated Publics," Hashtag Publics, Peter Lang US, pp. 1-22, 2015.

[46] A. Katal, M. Wazid, and R. H. Goudar, "Big data: Issues, Challenges, Tools and Good Practices," Sixth International Conference on Contemporary Computing, IEEE, pp. 404-409, 2013. Available: https://doi.org/10.1109/IC3.2013.6612229

[47] X. Wu, X. Zhu, G.-Q. Wu, and W. Ding, "Data Mining with Big Data," IEEE Transactions on Knowledge and Data Engineering, vol. 26, no.1, pp. 97-107, 2014. Available: https://doi.org/10.1109/TKDE.2013.109 
[48] R. Y. K. Lau, S. S. Y. Liao, K. F. Wong, and D. K. W. Chiu, "Web 2.0 Environmental Scanning and Adaptive Decision Support for Business Mergers and Acquisitions," MIS Quarterly, vol. 36, no. 4, pp. 1239-1268, 2012. Available: https://doi.org/10.2307/41703506

[49] M. Tenemaza, L.-A. Edison, M. Peñafiel, Z. Juan, A. de Antonio, and J. Ramirez, "Identifying Touristic Interest Using Big Data Techniques," Advances in Artificial Intelligence, Software and Systems Engineering, Springer, vol. 965, pp. 169-178, 2020. Available: https://doi.org/10.1007/978-3-030-20454-9_17

[50] W. A. Günther, M. H. Rezazade Mehrizi, M. Huysman, and F. Feldberg, "Debating Big Data: A Literature Review on Realizing Value from Big Data," The Journal of Strategic Information Systems, vol. 26, no. 3, pp. 191-209, 2017. Available: https://doi.org/10.1016/j.jsis.2017.07.003

[51] S. Akter, S. F. Wamba, A. Gunasekaran, R. Dubey, and S. J. Childe, "How to Improve Firm Performance Using Big Data Analytics Capability and Business Strategy Alignment?" International Journal of Production Economics, vol. 182, pp. 113-131, 2016. Available: https://doi.org/10.1016/j.ijpe.2016.08.018

[52] R. Likert, “A Technique for the Measurement of Attitudes,” Archives of Psychology, vol. 22, pp. 5-55, 1932.

[53] S.-Y. Lin, C.-C. Chiang, Z.-S. Hung, Y.-H. Zou, "A Dynamic Data-Driven Fine-Tuning Approach for Stacked Auto-Encoder Neural Network," 2017 IEEE 14th International Conference on e-Business Engineering (ICEBE), pp. 226-231, 2017. Available: https://doi.org/10.1109/ICEBE.2017.43

[54] T. C.-K. Huang, P.-T. Yang, and J.-H. Teng, "Change detection model for sequential cause-andeffect relationships," Decision Support Systems, vol. 106, pp. 30-43, $2018 . \quad$ Available: https://doi.org/10.1016/j.dss.2017.11.007

[55] T. S. J. Darwish and K. Abu Bakar, "Fog Based Intelligent Transportation Big Data Analytics in The Internet of Vehicles Environment: Motivations, Architecture, Challenges, and Critical Issues," IEEE Access, vol. 6, pp. 15679-15701, 2018. Available: https://doi.org/10.1109/ACCESS.2018.2815989

[56] C. Qin, H. Eichelberger, and K. Schmid, "Enactment of Adaptation in Data Stream Processing with Latency Implications - A Systematic Literature Review," Information and Software Technology, vol. 111, pp. 1-21, 2019. Available: https://doi.org/10.1016/j.infsof.2019.03.006

[57] O. Savas, Y. Sagduyu, J. Deng, and J. Li, "Tactical Big Data Analytics," ACM SIGMETRICS Performance Evaluation Review, vol. 41, no. 4, pp. 86-89, 2014. Available: https://doi.org/10.1145/2627534.2627561

[58] A. Bousdekis, N. Papageorgiou, B. Magoutas, D. Apostolou, and G. Mentzas, "Sensor-driven Learning of Time-Dependent Parameters for Prescriptive Analytics," IEEE Access, vol. 8, pp. 92383-92392, 2020. Available: https://doi.org/10.1109/ACCESS.2020.2994933

[59] N. Sachdeva, P. K. Kapur, and G. Singh, "Selecting appropriate cloud solution for managing big data projects using hybrid AHP-entropy based assessment," 2016 International Conference on Innovation and Challenges in Cyber Security (ICICCS-INBUSH), IEEE, pp. 135-140, 2016. Available: https://doi.org/10.1109/ICICCS.2016.7542351

[60] Z. Wang, Q. Xu, K. Ma, Y. Jiang, X. Cao, and Q. Huang, “Adversarial Preference Learning with Pairwise Comparisons," Proceedings of the 27th ACM International Conference on Multimedia, ACM, pp. 656-664, 2019. Available: https://doi.org/10.1145/3343031.3350919

[61] W. Noonpakdee, A. Phothichai, and T. Khunkornsiri, "Challenges of Big Data Implementation in a Public Hospital," 2019 28th Wireless and Optical Communications Conference (WOCC), IEEE, pp. 1-5, 2019. Available: https://doi.org/10.1109/WOCC.2019.8770562

[62] J. Wang, F. Liu, Y. Song, and J. Zhao, "A Novel Model: Dynamic Choice Artificial Neural Network (DCANN) for an Electricity Price Forecasting System," Applied Soft Computing, vol. 48, pp. 281-297, 2016. Available: https://doi.org/10.1016/j.asoc.2016.07.011

[63] S. Zhelev and A. Rozeva, "Using Microservices and Event Driven Architecture for Big Data Stream Processing," Proceedings of the 45th International Conference on Application of Mathematics in Engineering and Economics (AMEE '19), AIP Publishing, vol. 2172, no. 1, pp. 0900101-0900108, 2019. Available: https://doi.org/10.1063/1.5133587

[64] K. Adnan, R. Akbar, S. W. Khor, and A. B. A. Ali, "Role and Challenges of Unstructured Big Data in Healthcare," Data Management, Analytics and Innovatio. Advances in Intelligent Systems and Computing, Springer, vol. 1042, pp. 301-323, 2020. Available: https://doi.org/10.1007/978-981-32-9949-8_22

[65] U. Sivarajah, M. M. Kamal, Z. Irani, and V. Weerakkody, "Critical Analysis of Big Data Challenges and Analytical Methods," Journal of Business Research, vol. 70, pp. 263-286, 2017. Available: https://doi.org/10.1016/j.jbusres.2016.08.001 
[66] P. Aversa, L. Cabantous, and S. Haefliger, "When Decision Support Systems Fail: Insights for Strategic Information Systems from Formula 1," The Journal of Strategic Information Systems, vol. 27, no. 3, pp. 221236, 2018. Available: https://doi.org/10.1016/j.jsis.2018.03.002

[67] G. G. Claps, R. Berntsson Svensson, and A. Aurum, “On the Journey to Continuous Deployment: Technical and Social Challenges Along the Way," Information and Software Technology, vol. 57, pp. 21-31, 2015. Available: https://doi.org/10.1016/j.infsof.2014.07.009

[68] P. R. Kuruppuarachchi, P. Mandal, and R. Smith, "IT Project Implementation Strategies for Effective Changes: A Critical Review," Logistics Information Management, vol. 15, no. 2, pp. 126-137, 2002. Available: https://doi.org/10.1108/09576050210414006

[69] D. Moitra, "Managing Change for Software Process Improvement Initiatives: A Practical Experience-based Approach," Softw. Process: Improve. Pract., vol. 4, no. 4, pp. 199-207, 1998. Available: https://doi.org/10.1002/(SICI)1099-1670(199812)4:4<199::AID-SPIP107>3.0.CO;2-D

[70] N. Dragoni, S. Giallorenzo, A. L. Lafuente, M. Mazzara, F. Montesi, R. Mustafin, and L. Safina, "Microservices: Yesterday, Today, and Tomorrow," Present and Ulterior Software Engineering, Springer, pp. 195-216, 2017. Available: https://doi.org/10.1007/978-3-319-67425-4_12

[71] B. Familiar, Microservices, IoT, and Azure. Leveraging DevOps and Microservice Architecture to Deliver SaaS Solutions, Apress, New York, 2015. Available: https://doi.org/10.1007/978-1-4842-1275-2

[72] D. Staegemann, J. Hintsch, and K. Turowski, "Testing in Big Data: An Architecture Pattern for a Development Environment for Innovative, Integrated and Robust Applications," Proceedings of the WI2019, pp. 279-284, 2019.

[73] A. Freymann, F. Maier, K. Schaefer, and T. Böhnel, "Tackling the Six Fundamental Challenges of Big Data in Research Projects by Utilizing a Scalable and Modular Architecture," Proceedings of the 5th International Conference on Internet of Things, Big Data and Security, SCITEPRESS - Science and Technology Publications, pp. 249-256, 2020. Available: https://doi.org/10.5220/0009388602490256 